\title{
A New Hybrid LGPMBWM-PIV Method for Automotive Material Selection
}

\author{
Saif Wakeel ${ }^{1,2}$ and Sedat Bingol ${ }^{2}$ \\ ${ }^{1}$ Centre of Advanced Materials, Department of Mechanical Engineering \\ University of Malaya, Kuala Lumpur, Malaysia \\ ${ }^{2}$ Department of Mechanical Engineering, Dicle Universitesi, Diyarbakir, Turkey \\ E-mail: saifwakeel@gmail.com, sbingol@dicle.edu.tr \\ Shafi Ahmad \\ Department of Mechanical Engineering, Jamia Millia Islamia, New Delhi, India \\ E-mail: shafiahmad.amu@gmail.com \\ M. Nasir Bashir \\ National University of Sciences and Technology, Islamabad, Pakistan \\ E-mail: nasir@pnec.nust.edu.pk
}

Mir Seyed Mohammad Mohsen Emamat

Department of Industrial Management, Allameh Tabataba'i University, Tehran, Iran

E-mail: sm.emamat@gmail.com

Zhou Ding

Centre of Advanced Materials, Department of Mechanical Engineering

University of Malaya, Kuala Lumpur, Malaysia

H. Fayaz

Modeling Evolutionary Algorithms Simulation and Artificial Intelligence,

Faculty of Electrical and Electronics Engineering, Ton Duc Thang University, Ho Chi Minh City, Vietnam

E-mail: fayaz@tdtu.edu.vn

Keywords: natural fibres, car roof, automotive material selection, linear goal programming model for best-worst method (LGPMBWM), PIV method

Received: July 21, 2020

Efforts are continuously being made by researchers to improve fuel efficiency and to reduce $\mathrm{CO}_{2}$ emissions from the passenger cars. To achieve these goal, recent trend is to make the cars components light in weight for which manufacturing car roofs using natural fiber reinforced composites (NFCs) is one of the method. Several natural fibers (NFs) are available as alternative reinforcements for the fabrication of NFCs. Different NFs possess different properties and therefore, it is necessary to select the most appropriate natural fiber for fabrication of the composites which in turn will lead to the desired performance of the vehicle. Selection of the optimal natural fiber, amongst the several alternatives, is basically a multi criteria decision making (MCDM) problem as selection is based on the evaluation of several conflicting criteria. In this study, twelve alternative natural fibers (Flax, Hemp, Jute, Kenaf, Ramie, Okra, PALF, Coir, Isora, Cotton, Banana and Sisal) and six evaluation criteria (Tensile strength, Stiffness, Failure strain, Density, Degradation temperature and Moisture gain) are considered and selection of the optimal NF is made using a newly developed hybrid MCDM method i.e. Linear goal programming model for Best-Worst method (LGPMBWM) and Proximity index value method (PIV). Results of the study reveal that among all considered natural fibers, Ramie fiber is the most suitable alternative for the fabrication of composites and coir fiber is the worst candidate for the same. Ranking results were also supported by five other MCDM methods as there was a strong correlation between PIV and other MCDM methods.

Povzetek: V prispevku so opisali izvirno hibridno metodo za iskanje novih delov avtomobilskih motorjev.

\section{Introduction}

The temperature of earth is increasing due to the emission of global warming gases from various sources such as industries and different modes of transport. Production of transport vehicles needs four times less energy as compared to energy required to drive them during their complete service life [1]. Therefore, emissions from transports contribute major portion of global warming 
gases. However, the problem of global warming due to emissions from transports can be minimized by improving their performance in terms of fuel economy which can be achieved by reducing their weight to strength ratio [2]. Consequently, it is suggested to produce light weight vehicles with increased strength. The weight of the vehicular transports can be minimized by using appropriate materials in their production. Thus, it is imperative to select the best material from the existing numerous materials to achieve the objective of making vehicles light in weight.

The car roof is usually encountered with dangerous rollover accidents due to which the occupants get serious head and neck injuries and sometimes the accident is so fatal that they lose their life [3]. Therefore, for safety of passengers, it is necessary to ensure that the car roof is sufficiently strong to withstand the impact in the event of an accident. Toughness of steel sheet is relatively poor which leads to transfer of shocking load to occupants from car roof during accident. Therefore, materials with high value of toughness such as plastic based composite materials are suggested for car roof manufacturing. It has been reported that composites such as Kevlar fiber /Epoxy, carbon fiber/Epoxy and Boron fiber/epoxy possess high tensile and flexural strengths as compared to aluminum and steel [4]. For manufacturing of car roof, thermoset and thermoplastic base fiber reinforced composites have favorable properties such as light in weight, higher toughness and good flexural strength. Generally, composite has high resistance for corrosion as compared to commercial grade of steel which is an additional benefit that restricts deterioration of material of the automotive components such as car roof by corrosion phenomenon which ultimately leads to improved service life of the automotive vehicles.

Selection of a suitable material is based on several desirable conflicting attributes. Therefore, material selection is a multi-criteria decision making problem (MCDM) which needs to be solved by using appropriate MCDM method. Literature reveals that past researchers have used several MCDM methods for solving various problems pertaining to different field of applications. AlOqlaand Sapuan [5] employed Analytical Hierarchy Process (AHP) to select the best natural fiber (NF) among coir, date, palm, hemp, flax and sisal for sustainable automotive industry and found that Flax was the best alternative material followed by date palm fiber. AlOqlaet al [6] used AHP method for the selection of best polymer based matrix to form flax and date palm reinforced natural fiber composite and found that polypropylene (PP) as the best matrix material. Al-Oqlaet al [7] applied AHP method for the selection of best natural fiber for polypropylene based NFCs and reported that flax fiber was the best reinforcing agent for polypropylene matrix. Maskepatil et al [8] employed AHP method for selection of the most suitable material among wood, steel, aluminium, glass fiber and carbon fiber for designing wind turbine blade and observed that carbon fiber was the best choice for the same. Luqmanet al [9] used AHP method to determine best suitable composite fabrication method to manufacture carbon fiber crank arm of bicycle and observed that compression moulding process was the best choice among all the manufacturing processes. Anojkumar et al [10] employed four different methods: TOPSIS, VIKOR, Electre computational and PROMTHEE computational for the selection of best steel material for pipe manufacturing in sugar industry and found that M 304 steel grade was best suited steel grade among all five steel grades. Anupam et al[11]successfully applied TOPSIS method for selecting optimum material for pulp and paper making industry. Al-Oqla et al [12] successfully investigated the best reinforcing condition for fabrication of NFCs using TOPSIS and AHP method and suggested the importance of $\mathrm{NaOH}$ treatment for fabrication of NFCs. Majumdar et al [13] applied AHP for selection of best cotton among Cotton grades (A to $\mathrm{H}$ ) and suggested Cotton D as the best alternative. Ozturk et al[14] selected light weight fabric from natural cellulose composite employing weighted sum method. Mohammed et al [15] employed TOPSIS method for selecting best glass fiber reinforced epoxy hybrid composite and suggested Glass + epoxy $+5 \%$ coal fly ash as the best feasible composite. Jha et al[16] selected optimal biodegradable composite among many composites formed by pine cone with graphite content $(0,5,10,15 \%)$ /Polycaprolactone using fuzzy TOPSIS method and their result clearly showed that Polycaprolactone/ pine cone + graphite $(0 \%)$ composite was a suitable choice. Getting motivated from the wide application of AHP and TOPSIS methods, Ahmed [17] developed a Java scripted MCDM weight range method for selection of NFCs material for door panel and suggested that Sisal 30\%-PP was suitable NFC. Ishak et al [18] employed fuzzy VIKOR method for selection of NFs for car front hood and the result of their study revealed that kenaf fiber was suitable choice for designing of car front hood. Besides, MCDM methods have also been used in other environments. Chang [19] selected the most suitable public relations personal for tourism industry using hybrid fuzzy Delphi-ANP-TOPSIS method. Chakraborty and Zavadskas [20] successfully used WASPAS method for ranking the alternative involve in the parameter selection of eight machining problem namely, cutting fluid, electrospinning, forging conditions, arc welding process, industrial robot, milling conditions, machinability of materials and process parameters selection for electro-discharge micro machining. Selection of new and right technology for industrial sustainability was done using hybrid fuzzy-ANP and fuzzy- TOPSIS method [21]. Keshavarz et al. [22] applied a EDAS method for solving the multi-criteria inventory classification problem.

From the available literature it is observed that MCDM techniques can be used efficiently for material selection. However, each technique have certain advantages and limitations such as AHP and TOPSIS have rank reversal problem. VIKOR has problem associated with closeness of alternatives from ideal which prompted us to use the recently developed PIV method. PIV method eliminates the rank reversal problem and include short steps. Besides, original BWM has $4 n-5$ number of constraints ( $\mathrm{n}$ is number of criteria) however, recently developed LGPMBWM consist of $2 n-2$ 
constraints which minimizes the computational complexity and gives better consistency results as compared to original BWM method. To the best of author's knowledge, this kind of technique has never been used for automobile material selection problem. Therefore, recently developed LGPMBWM-PIV method has been applied in this study for ranking the alternative natural fiber to formulate the car roof polymer composite on the basis of various conflicting criteria. As a result of this study, best suited natural fiber was selected among all the alternative materials. Consequently, sensitivity analysis has been performed successfully to verify the results of this MCDM method and their results showed that technique applied is reliable and consistent.

\section{Methodology}

The methodology adopted for solving the ranking problem of the selected natural fibers is depicted in the research framework shown in Fig. 1.

The details of criteria selection, criteria weights calculation, and different methods used for ranking of alternatives are given in the following sections.

\subsection{Selection of criteria for car roof materials}

On the basis of car rollover testing, fabrication process temperature, strength to weight ratio and delamination process of NFCs, six criteria (shown in Table.1) are taken in account. As a first criterion, density of reinforcing phase i.e. natural fibres have direct effect on strength to weight ratio of composites used for car roof manufacturing which leads to fuel economy of the vehicles. Therefore, there is a need to minimize the density of the reinforcing phase of the composite to attain better strength to weight ratio. Consequently, density is considered as an important nonbeneficial criteria for selection of natural fibre. Second criterion is tensile strength of natural fiber and it is observed that tensile strength of car roof composite (NFC) mainly depends on tensile strength of the reinforcing phase i.e. natural fibres [23]. Therefore, tensile strength of

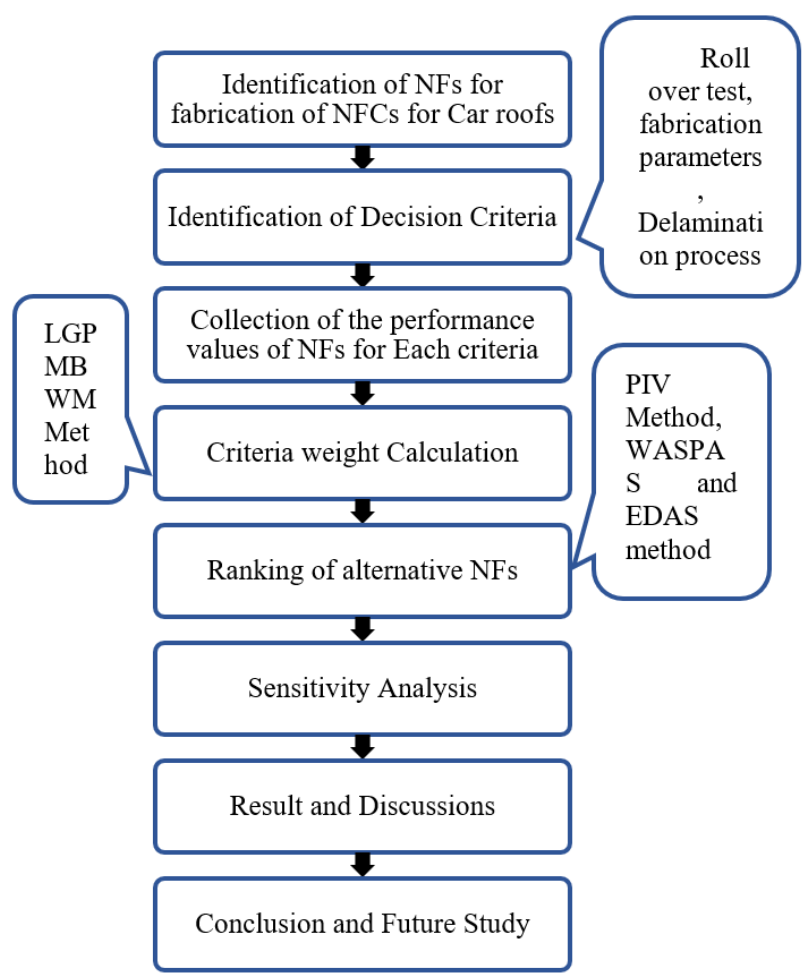

Figure 1: Research Framework.

the natural fibres is considered as an important beneficial criteria. Third criterion is the stiffness of NFCs which is mainly governed by reinforcing phase i.e. natural fibres. The design of lightweight structures such as car roofs requires the use of NFCs having greater stiffness [24]. Therefore, it is necessary to maximize the value of stiffness for natural fibre to fabricate a composite for car roof manufacturing which has greater value of stiffness. Value of Failure strain of composite materials is significantly depends on the reinforcing agent i.e. natural fibres. The composite materials used to manufacture car roofs must have good value for toughness and toughness of composite materials is also depends on failure strain of natural fibres. Therefore, it is necessary to include failure strain of natural fibres in criteria. TGA analysis showed that every natural fibre have different thermal degradation

\begin{tabular}{|c|c|c|c|c|c|c|}
\hline Alternative NFs & $\begin{array}{l}\text { Tensile } \\
\text { Strength } \\
\text { (TS) in } \\
\mathrm{MPa}\end{array}$ & $\begin{array}{c}\text { Stiffness }(\mathrm{S}) \\
\text { in } \\
\mathrm{GPa}\end{array}$ & $\begin{array}{c}\text { Failure } \\
\text { Strain } \\
\text { (FS) in } \\
\%\end{array}$ & $\begin{array}{l}\text { Density } \\
\text { (D) in } \\
\mathrm{g} / \mathrm{cm}^{3}\end{array}$ & $\begin{array}{c}\text { Degradation } \\
\text { Temperature (DT) } \\
\text { in } \\
{ }^{0} \mathrm{C}\end{array}$ & $\begin{array}{c}\text { Moisture } \\
\text { Gain (M) in } \\
\%\end{array}$ \\
\hline Goal & $(+)$ & $(+)$ & $(-)$ & $(-)$ & $(+)$ & $(-)$ \\
\hline $\operatorname{Flax}(F)$ & 975 & 32.8 & 2.35 & 1.52 & 250 & 12 \\
\hline $\operatorname{Hemp}(\mathrm{H})$ & 781.5 & 9.93 & 3.15 & 1.48 & 250 & 12 \\
\hline Jute(J) & 583 & 14.5 & 1.5 & 1.375 & 205 & 17 \\
\hline Kenaf(K) & 423.5 & 12.75 & 4.2 & 1.4 & 219 & 17 \\
\hline Ramie(R) & 669 & 76.35 & 2.5 & 1.45 & 300 & 8.5 \\
\hline $\mathrm{Okra}(\mathrm{O})$ & 307 & 9 & 1.95 & 0.88 & 220 & 13 \\
\hline PALF(P) & 170 & 62.1 & 3 & 1.52 & 220 & 14 \\
\hline Coir $(\mathrm{C})$ & 140.5 & 6 & 22.5 & 1.25 & 190 & 13 \\
\hline Isora(I) & 580.5 & 20.5 & 5.5 & 1.37 & 220 & 1.2 \\
\hline Cotton $(\mathrm{CO})$ & 500 & 8 & 7 & 1.55 & 220 & 8.5 \\
\hline Banana(B) & 750 & 29.5 & 2.95 & 1.3 & 200 & 13.5 \\
\hline Sisal(S) & 460 & 15.5 & 8 & 1.4 & 300 & 14 \\
\hline
\end{tabular}

Table.1 Properties of selected Natural fibres [23-39]. 


\begin{tabular}{llllllllll}
\hline$a_{B W}$ & 1 & 2 & 3 & 4 & 5 & 6 & 7 & 8 & 9 \\
\hline consistency index & 0.00 & 0.44 & 1.00 & 1.63 & 2.30 & 3.00 & 3.73 & 4.47 & 5.23 \\
\hline
\end{tabular}

Table 2. Consistency index.

temperature because of the difference in their activation energy which depends on their chemical composition [25]. Generally, Natural fibres degrade at low temperature as compared to synthetic fibres. Available literature revealed that thermoplastic matrix based composites need higher processing temperature during fabrication therefore, it is suggested to improve the thermal degradation temperature of the reinforcing agent i.e. natural fibre by choosing the appropriate natural fibre. Consequently, thermal degradation temperature of natural fibres is necessary to include in the required beneficial criteria of composite which is used to manufacture roofs of the car. Natural fibres have hydrophilic nature due to which they gain moisture contents but the chemical composition of natural fibres are different to each other which leads to differences in percentage of moisture gain by the natural fibres. The interfacial shear strength (IFSS) of the natural fibre composites is significantly influenced by moisture contents of natural fibres [26]. It has been observed that IFSS of the NFCs shows deterioration for moisture gain by natural fibres [27]. In NFCs, it is suggested to minimize or eliminate the moisture contents of reinforcing agents i.e. natural fibres. Consequently, percentage of moisture gain by natural fibres is an important criteria for selections of natural fibres to insure the IFSS of NFCs which is used to manufacture car roofs.

In this study, twelve natural fibers (listed in Table 1) with their different attributes/properties have been considered as available alternatives being used for fabrication of composites for car roof manufacturing. These fibers are eco-friendly, biodegradable and their abundance and light weight make them suitable to be used in automotive, aerospace and sports industries.

In order to rank the natural fibers, it is necessary to evaluate the weights of criteria which can be done by various methods but in our study simple, consistent and reliable LGPMBWM method is employed for the weight calculation. The comprehensive study of LGPMBWM is explained in the following section.

\subsection{Linear goal programming model for best worst method (LGPMBWM)}

In this study, recently developed linear goal programming model for best-worst method (LGPMBWM) [40] is employed for weight calculation which involves the selection of best (most important criterion) and worst factor (least important criterion) and their comparison with other criteria on the basis of comparison scale from 1 to 9. Thus, this comparison leads to the formation of two pairwise comparison vector i.e. Best to Others (BO) and Others to Worst (OW) vectors. Further, using LGPMBWM the optimal weights of criteria and consistency are calculated. The BWM has certain advantages over the other methods as [41]; (i) It provides minimum total deviation and thereby ensures closer weight ratios, (ii) It provides consistent comparisons, and (iii) In comparison to AHP, it provides minimum violation i.e. better ordinal consistency. Based on the significant advantages of BWM, researchers have used this method for calculating weight of criteria in various applications [42-50]. In addition to these advantages, the LGPMBWM has $2 n-2$ number of constraints while the original BWM had $4 n-5$ number of constraints ( $n$ is the number of criteria). The LGPMBWM has fewer constraints in comparison with the BWM, which results in improved computational solution and reducing the complexity in original BWM. Further, detail of this method can be found in work done by its developer [40].

However, it is necessary to provide the steps of this method for visualizing the clear picture behind its use in present research.

Step 1: Identify n decision criteria $\left\{\mathrm{C}_{1}, \mathrm{C}_{2}, \ldots, \mathrm{C}_{\mathrm{n}}\right\}$ for making decision. In decision making problem of natural fibers selection for Car roof, criteria are as follows: Tensile Strength (TS), Stiffness (S), Failure Strain (FS), Density (D), Degradation Temperature (DT) and Moisture Gain (M).

Step 2: Select the best and the worst criteria. In this study best and worst factors have been selected on the basis of academic expert advice.

Step 3: In this step, pairwise comparison is done between best criterion and other criteria by using numbers between 1 to 9 (1: equally important, 2: weakly important, 3: moderately important, 4 : moderately plus important, 5 : strongly important, 6: strongly plus important, 7: very strongly important, 8: very, very strongly important 9: extremely important) to determine the importance of the best criterion over others which leads to the formation of best to others $(\mathrm{BO})$ vector as:

$$
A_{B}=
$$

$\left(a_{B 1}, a_{B 2}, a_{B 3} \ldots . a_{B n}\right)$

Where, $a_{B}$ is the best to others (BO) vector and $a_{\mathrm{Bj}}=$ Importance of best criterion over the $\mathrm{j}^{\mathrm{t}}$ criterion. It is obvious that $a_{\mathrm{BB}}=1$.

Step 4: Comparison of all the criteria with the worst criterion is done in same way as in step 3 which leads to the formation of others-to-worst (OW) vector as:

$$
A_{\mathrm{w}}=\left(a_{1 w}, a_{2 w}, a_{3 w} \ldots . a_{n w}\right)^{\mathrm{T}}
$$

where $a_{\mathrm{jw}}=$ importance of $\mathrm{j}^{\text {th }}$ criterion with respect to the worst criterion. It is evident that $a_{\mathrm{ww}}=1$.

Step 5: The final step is to calculate the optimal weights $\left(\mathrm{w}_{1}{ }^{*}, \mathrm{w}_{2}{ }^{*}, \ldots, \mathrm{w}_{\mathrm{n}}{ }^{*}\right)$. The amount of inconsistency is reflected to $y_{j}^{+}-\bar{y}_{j}$ and $z_{j}^{+}-z_{j}$ for indicating the preference of $\mathrm{BO}$ and $\mathrm{OW}$. The objective function of LGPMBWM is also about minimizing total deviations. The

LGPMBWM model is presented as Eq. (3). 


$$
\begin{gathered}
\min z=\sum_{j}\left(y_{j}^{+}+\overline{y_{j}}\right)+\sum_{j}\left(z_{j}^{+}+\overline{z_{j}}\right) \\
\text { subject to: } \\
w_{B}-a_{B j} w_{j}=y_{j}^{+}-y_{j}, \text { for all } \mathrm{j}, \\
w_{j}-a_{j w} w_{w}=z_{j}^{+}-z_{j}
\end{gathered}
$$$$
\text { forall }
$$$$
\text { (3) }
$$$$
\sum_{j} \mathrm{w}_{\mathrm{j}}=1
$$$$
w_{j}, y_{j}^{+}, \bar{y}_{j}, z_{j}^{+}, z_{j} \geq 0 \text {, for all } \mathrm{j} .
$$

Step 6: The consistency ratio can be calculated by Eq. (4) and (5). We also use Table 2 to obtain the consistency index. A value of consistency ratio close to zero indicates a high degree of consistency and vice versa.

$$
\begin{aligned}
& \xi=\max _{j}\left\{y_{j}^{+}-\bar{y}_{j}, z_{j}^{+}+z_{j}\right\}_{\xi} \\
& \text { consistency ratio }=\frac{\xi \text { consistency index }}{}
\end{aligned}
$$

\subsection{Proximity Index Value Method (PIV)}

Proximity Index Value (PIV) method has been developed by [51]. This method has advantage of minimizing the rank reversal phenomenon over TOPSIS method. Further, the computational steps involved in PIV method are less as well as simpler than TOPSIS method. Owing to these advantages of PIV method which is a recent method, it has been used in this study. This method involves the following simple steps:

Step 1: Identify the available alternatives $A_{i}(i=1,2, \ldots$, $\mathrm{m})$ and decision criteria $\mathrm{C}_{\mathrm{j}}(\mathrm{j}=1,2, \ldots, \mathrm{n})$ involved in the decision problem.

Step 2: Formulate the decision matrix $Y$ by arranging alternatives in rows and criteria in columns as given in Eq.(6).

where, $Y_{i j}$ represents $i^{\text {th }}$ alternative performance value on $\mathrm{j}^{\text {th }}$ criterion, $\mathrm{m}$ is the number of alternatives, and $\mathrm{n}$ is the number of criteria.

Step 3: Normalized Performance value of each alternative for a given criterion against the performance of remaining alternatives is calculated by taking performance value of one alternative with respect to performances of all the alternatives for the same criterion and mathematically it can be expressed by Eq. (7).

$$
\mathrm{y}_{\mathrm{ij}}^{*}=\frac{\mathrm{y}_{\mathrm{ij}}}{\sqrt{\sum_{1}^{\mathrm{m}} \mathrm{y}^{2}{ }_{\mathrm{ij}}}}
$$

where, $\mathrm{y}_{\mathrm{ij}}^{*}=$ Normalized performance of $i^{\text {th }}$ alternative ofj ${ }^{\text {th }}$ criterion, $y_{i j}=$ performance value of $\mathrm{i}^{\text {th }}$ alternative on $\mathrm{j}^{\text {th }}$ criterion.

Step 4: In order to calculate the weighted normalized performance value, weight of the criterion has been calculated using Best-Worst method and then weighted normalized performance value of $\mathrm{i}^{\text {th }}$ alternative on the $\mathrm{j}^{\text {th }}$ criterion is calculated by Eq.(8).

$$
\mathrm{V}_{\mathrm{ij}}=\mathrm{y}_{\mathrm{ij}}^{*} \times \mathrm{W}_{\mathrm{j}}
$$

where $V_{i j}$ is the weighted normalized value and $W_{j}$ is the weight of criterion

Step 5: Evaluate the Weighted Proximity Index (WPI), $u_{i}$ using Eq. (9) which is determined by taking the difference of weighted normalized value from its maximum/minimum value $\left(\mathrm{v}_{\mathrm{ijmax}}, \mathrm{v}_{\mathrm{ijmin}}\right)$ in its range $u_{i}=\left\{\begin{array}{c}v_{i j m a x}-v_{i j} ; \text { for beneficial attributes } \\ v_{i j}-v_{i j m i n} ; \text { for cost attributes }\end{array}\right\}$

Step 6: Overall proximity value $\left(\mathrm{d}_{\mathrm{i}}\right)$ which determines the closeness of the available alternative w.r.t best alternative and given by taking the overall sum of all the weighted performance index value $\left(\mathrm{u}_{\mathrm{i}}\right)$ given in Eq.(10).

$$
\mathrm{d}_{\mathrm{i}}=\sum_{\mathrm{j}=1}^{\mathrm{n}} \mathrm{u}_{\mathrm{i}}
$$

Step 7: Ranking of the alternatives on the basis of $d_{i}$ values. The alternative with least value of $d_{i}$ represents minimum deviation from the best and therefore, it is ranked first, followed by alternatives with increasing $d_{i}$.

\section{Results and Discussion}

\subsection{Results of LGPMBWM-PIV Method}

Decision matrix of this problem is shown in Table 1 which reveals twelve alternative natural fibers i.e. flax, hemp, jute, kenaf, ramie, okra, pine apple leaf fibre (PALF), coir, isora, cotton, banana and sisal and six decision criteria viz tensile strength (TS), Stiffness (S), failure strain (FS), density (D), thermal degradation temperature (TD) and percentage moisture gain $(\mathrm{M})$.

In order to evaluate the importance and comparison of criteria with each other, Academic experts from various university and industry are interviewed and they were asked to select the best and worst criterion for Car roof

$$
\mathrm{Y}=\left[\mathrm{Y}_{\mathrm{ij}}\right]_{\mathrm{m} \times \mathrm{n}}=\left[\begin{array}{cccccc}
\mathrm{Y}_{11} & \mathrm{Y}_{12} & \ldots & \mathrm{Y}_{1 \mathrm{j}} & \ldots & \mathrm{Y}_{1 \mathrm{n}} \\
\mathrm{Y}_{21} & \mathrm{Y}_{22} & \ldots & \ldots & \ldots & \mathrm{Y}_{2 \mathrm{n}} \\
\ldots & \ldots & \ldots & \ldots & \ldots & \ldots \\
\mathrm{Y}_{\mathrm{i} 1} & \ldots & \ldots & \mathrm{Y}_{\mathrm{ij}} & \ldots & \mathrm{Y}_{\mathrm{in}} \\
\ldots & \ldots & \ldots & \ldots & \ldots & \ldots \\
\mathrm{Y}_{\mathrm{m} 1} & \ldots & \ldots & \mathrm{Y}_{\mathrm{mj}} & \ldots & \mathrm{Y}_{\mathrm{mn}}
\end{array}\right]
$$

where, $\quad \mathrm{i}=1,2, \ldots, \mathrm{m} ; \mathrm{j}=1,2, \ldots, \mathrm{n}$

based on their experience related to automotive area. Thus, best and worst criteria identified by these expert are listed in Table 3.

\begin{tabular}{lccc}
\hline Factors & $\begin{array}{l}\text { Identified } \\
\text { 'Best' } \\
\text { Expert No. }\end{array}$ & $\begin{array}{l}\text { as } \\
\text { by }\end{array}$ & $\begin{array}{l}\text { Identified } \\
\text { 'Worst' } \\
\text { Expert No. }\end{array}$ \\
\hline $\begin{array}{l}\text { Tensile strength } \\
\text { (TS) }\end{array}$ & 4 & 5 \\
Stiffness (S) & $1,2,5,6$ & \\
Failure strain (FS) & 3 & 2 \\
Density (D) & & \\
Degradation & & $3,4,6$ \\
temperature (DT) & & \\
Moisture gain (M) & & 1 \\
\hline
\end{tabular}




\begin{tabular}{llllllll}
\hline Expert No & TS & S & FS & D & DT & M & Consistency ratio \\
\hline $\mathbf{1}$ & 0.1952 & 0.3903 & 0.0781 & 0.1952 & 0.1301 & 0.0112 & 0.0554 \\
$\mathbf{2}$ & 0.1206 & 0.4824 & 0.0151 & 0.2412 & 0.0804 & 0.0603 & 0.0663 \\
$\mathbf{3}$ & 0.1842 & 0.1228 & 0.3684 & 0.1842 & 0.0175 & 0.1228 & 0.0403 \\
$\mathbf{4}$ & 0.5680 & 0.1136 & 0.1420 & 0.0811 & 0.0142 & 0.0811 & 0.0842 \\
$\mathbf{5}$ & 0.0239 & 0.5972 & 0.0853 & 0.0746 & 0.1194 & 0.0995 & 0.0731 \\
$\mathbf{6}$ & 0.1838 & 0.5234 & 0.0748 & 0.1308 & 0.0218 & 0.0654 & 0.0625 \\
Average & 0.2126 & 0.3716 & 0.1273 & 0.1512 & 0.0639 & 0.0734 & 0.0636 \\
\hline
\end{tabular}

Table 6: Optimal weights of criteria and consistency ratio.

\begin{tabular}{lllllll}
\hline Alternative NFs & TS & S & FS & D & DT & M \\
\hline Goal & $(+)$ & $(+)$ & $(-)$ & $(-)$ & $(+)$ & $(-)$ \\
\hline F & 0.4856 & 0.2883 & 0.0880 & 0.3167 & 0.3066 & 0.2736 \\
H & 0.3892 & 0.0873 & 0.1180 & 0.3084 & 0.3066 & 0.2736 \\
J & 0.2903 & 0.1274 & 0.0562 & 0.2865 & 0.2514 & 0.3875 \\
K & 0.2109 & 0.1121 & 0.1573 & 0.2917 & 0.2686 & 0.3875 \\
R & 0.3332 & 0.6711 & 0.0937 & 0.3021 & 0.3680 & 0.1938 \\
O & 0.1529 & 0.0791 & 0.0730 & 0.1834 & 0.2698 & 0.2964 \\
P & 0.0847 & 0.5458 & 0.1124 & 0.3167 & 0.2698 & 0.3192 \\
C & 0.0700 & 0.0527 & 0.8429 & 0.2605 & 0.2330 & 0.2964 \\
I & 0.2891 & 0.1802 & 0.2060 & 0.2855 & 0.2698 & 0.0274 \\
CO & 0.2490 & 0.0703 & 0.2622 & 0.3230 & 0.2698 & 0.1938 \\
B & 0.3735 & 0.2593 & 0.1105 & 0.2709 & 0.2453 & 0.3078 \\
S & 0.2291 & 0.1362 & 0.2997 & 0.2917 & 0.3680 & 0.3192 \\
\hline
\end{tabular}

Table 7: Normalized decision matrix for Car roof NF's problem.

Table 3: Best and Worst Criteria Identified by Experts from 1 to 6 .

Based on the expert interview, identification of best vector and its comparison with other vectors is done using Eq.(1) and pairwise comparison matrix is formulated as depicted in Table 4.

\begin{tabular}{llllllll}
\hline $\begin{array}{l}\text { Expert } \\
\text { No. }\end{array}$ & Best & TS & S & FS & D & DT & M \\
\hline $\mathbf{1}$ & S & 2 & 1 & 5 & 2 & 3 & 9 \\
$\mathbf{2}$ & S & 4 & 1 & 9 & 2 & 6 & 8 \\
$\mathbf{3}$ & FS & 2 & 3 & 1 & 2 & 9 & 3 \\
$\mathbf{4}$ & TS & 1 & 5 & 4 & 7 & 9 & 7 \\
$\mathbf{5}$ & S & 9 & 1 & 7 & 8 & 5 & 6 \\
$\mathbf{6}$ & S & 2 & 1 & 7 & 4 & 9 & 8 \\
\hline
\end{tabular}

Table 4: Best to Others (BO) pairwise comparison matrix.

Similarly, Expert interview revealed the identification of worst factor and the comparison of other criteria with respect to worst factor using Eq.(2) is shown in Table 5.

\begin{tabular}{lllllll}
\hline $\begin{array}{l}\text { Expert } \\
\text { No. }\end{array}$ & $\mathbf{1}$ & $\mathbf{2}$ & $\mathbf{3}$ & $\mathbf{4}$ & $\mathbf{5}$ & $\mathbf{6}$ \\
\hline Worst & M & FS & DT & DT & TS & DT \\
\hline TS & 7 & 8 & 8 & 9 & 1 & 8 \\
S & 9 & 9 & 7 & 8 & 9 & 9 \\
FS & 7 & 1 & 9 & 7 & 2 & 3 \\
D & 8 & 7 & 7 & 3 & 1 & 6 \\
DT & 7 & 3 & 1 & 1 & 5 & 1 \\
M & 1 & 2 & 6 & 3 & 4 & 2 \\
\hline
\end{tabular}

Table 5: Others to Worst factor (OW) pairwise comparison matrix.

Based on the Pairwise comparison matrices shown in Table 4 and 5, final optimal weights and consistency are calculated using Eq. (3), (4) and (5) presented in Table 6. In the table, last row gives the final average optimal weights of all the criteria whereas last column gives consistency ratio.

Normalized decision matrix is formed by using Eq. (6), (7) and depicted in Table 7. In table (+) represents the beneficial criteria whereas (-) is for non-beneficial criteria.

Ranking of the NF's was done based on the proximity value by employing the Eq. (8), (9)\& (10) as given in the Table 8 .

Table 8 clearly shows that best available alternative material for the design of Car roof is ramie $(\mathrm{R})$ natural fiber whereas worst choice for the Car roof material among all the NF's is Coir (C) fiber. There are plethora of reasons behind the ranking but some of the highlighted reasons can be (a) Maximum Stiffness ( $76 \mathrm{GPa})$ of 


\begin{tabular}{lllllllll}
\hline & $\begin{array}{l}\text { TS } \\
(+)\end{array}$ & $\begin{array}{l}\text { S } \\
(+)\end{array}$ & $\begin{array}{l}\text { FS } \\
(-)\end{array}$ & $\begin{array}{l}\text { D } \\
(-)\end{array}$ & $\begin{array}{l}\text { DT } \\
(+)\end{array}$ & $\begin{array}{l}\text { M } \\
(-)\end{array}$ & $\begin{array}{l}\text { Proximity } \\
\text { Value }\end{array}$ & Rank \\
\hline F & 0.0000 & 0.1422 & 0.0041 & 0.0202 & 0.0039 & 0.0181 & 0.1884 & 3 \\
H & 0.0205 & 0.2169 & 0.0079 & 0.0189 & 0.0039 & 0.0181 & 0.2862 & 6 \\
J & 0.0415 & 0.2020 & 0.0000 & 0.0156 & 0.0074 & 0.0264 & 0.2930 & 7 \\
K & 0.0584 & 0.2077 & 0.0129 & 0.0164 & 0.0063 & 0.0264 & 0.3282 & 10 \\
R & 0.0324 & 0.0000 & 0.0048 & 0.0180 & 0.0000 & 0.0122 & 0.0673 & 1 \\
O & 0.0707 & 0.2200 & 0.0021 & 0.0000 & 0.0063 & 0.0197 & 0.3189 & 8 \\
P & 0.0852 & 0.0465 & 0.0072 & 0.0202 & 0.0063 & 0.0214 & 0.1868 & 2 \\
C & 0.0884 & 0.2298 & 0.1001 & 0.0117 & 0.0086 & 0.0197 & 0.4583 & 12 \\
I & 0.0418 & 0.1824 & 0.0191 & 0.0154 & 0.0063 & 0.0000 & 0.2650 & 5 \\
CO & 0.0503 & 0.2232 & 0.0262 & 0.0211 & 0.0063 & 0.0122 & 0.3394 & 11 \\
B & 0.0238 & 0.1530 & 0.0069 & 0.0132 & 0.0078 & 0.0206 & 0.2254 & 4 \\
S & 0.0545 & 0.1987 & 0.0310 & 0.0164 & 0.0000 & 0.0214 & 0.3221 & 9 \\
\hline & & & & & & & &
\end{tabular}

Table 8: Final ranking of NF's obtained through PIV method.

\begin{tabular}{lllllll}
\hline Alternative & PIV & WASPAS & TOPSIS & EDAS & ROV & COPRAS \\
\hline F & 3 & 2 & 3 & 3 & 2 & 3 \\
H & 6 & 7 & 7 & 7 & 6 & 7 \\
J & 7 & 6 & 6 & 6 & 8 & 6 \\
K & 10 & 10 & 9 & 10 & 10 & 10 \\
R & 1 & 1 & 1 & 1 & 1 & 1 \\
O & 8 & 8 & 8 & 8 & 7 & 8 \\
P & 2 & 4 & 2 & 2 & 4 & 2 \\
C & 12 & 12 & 12 & 12 & 12 & 12 \\
I & 5 & 5 & 5 & 5 & 5 & 5 \\
CO & 11 & 11 & 11 & 11 & 11 & 11 \\
B & 4 & 3 & 4 & 4 & 3 & 4 \\
S & 9 & 9 & 10 & 9 & 9 & 9 \\
\hline
\end{tabular}

Table 9: Ranking of alternative using PIV, WASPAS, EDAS, TOPSIS, ROV and COPRAS methods.

\begin{tabular}{l|ccccc}
\hline MCDM methods & WASPAS & TOPSIS & EDAS & ROV & COPRAS \\
\hline Correlation coefficient & 0.9860 & 0.9510 & 0.9860 & 0.9720 & 0.9930 \\
\hline
\end{tabular}

Table 10: Correlation between ranks obtained using PIV method with other MCDM methods.

Ramie fiber whereas, Coir has lowest stiffness ( $6 \mathrm{GPa})$, Car roof is a critical part of car which is subjected to high aerodynamics forces which can be major reason behind the bending of car roof. Therefore, it is necessary that sustainable fiber being used for car roof should be highly stiff in order to withstand against all the bending forces acting on Car roof, (b) Tensile strength of Ramie fiber is $\sim^{*} 4$ times greater than the tensile strength of Coir fiber which is also one of the major reason and (c) Natural fiber should have minimal moisture gain to obtained good interfacial integrity between $\mathrm{NF}$ reinforcement and the polymer matrix for successful fabrication of NFC. In this study, ramie fiber has lowest moisture gain $\sim 8 \%$ whereas coir has high moisture gain therefore, ramie fiber is suitable choice for natural fiber reinforced composite being used for car roof. Properties of other fibers is lying in between ramie and coir fiber so they are ranked accordingly.

\subsection{Comparison with other MCDM methods}

Since, PIV is a newly developed method, the ranking results obtained from PIV method are compared with the ranks obtained with existing methods namely weighted aggregated sum product assessment (WASPAS), technique for order by preference by similarity to ideal solution (TOPSIS), Evaluation based on distance from average solution (EDAS), Range of value (ROV) and Complex proportional assessment (COPRAS) method. The details of these methods can be found in literature [5257]. The ranking results are shown in Table 9.

It has been observed again from Table 9 that the best available alternative material for the design of car roof is ramie $(\mathrm{R})$ natural fiber. Whereas, worst choice for the car roof material among all the NF's is Coir (C) fiber using all the six methods. Further, there is very few variation in the ranks of other NF's. Subsequently, correlation coefficient which is a statistical parameter used to measure relationship between two measures is computed for the ranks of NFs using different methods. The correlation 


\begin{tabular}{lccccccccccc}
\hline Criterion & $\begin{array}{c}\text { Normal } \\
(\mathbf{0 . 3 2 7 4 )}\end{array}$ & \multicolumn{1}{l}{ Modified weights of all indicators when the weight of S is varied from 0.1 to 0.9} \\
\hline TS & 0.2126 & 0.3045 & 0.2707 & 0.2368 & 0.2030 & 0.1692 & 0.1353 & 0.1015 & 0.0677 & 0.0338 \\
S & 0.3716 & 0.1000 & 0.2000 & 0.3000 & 0.4000 & 0.5000 & 0.6000 & 0.7000 & 0.8000 & 0.9000 \\
FS & 0.1273 & 0.1823 & 0.1621 & 0.1418 & 0.1215 & 0.1013 & 0.0810 & 0.0608 & 0.0405 & 0.0203 \\
D & 0.1512 & 0.2165 & 0.1925 & 0.1684 & 0.1444 & 0.1203 & 0.0962 & 0.0722 & 0.0481 & 0.0241 \\
DT & 0.0639 & 0.0915 & 0.0813 & 0.0712 & 0.0610 & 0.0508 & 0.0407 & 0.0305 & 0.0203 & 0.0102 \\
M & 0.0734 & 0.1051 & 0.0934 & 0.0818 & 0.0701 & 0.0584 & 0.0467 & 0.0350 & 0.0234 & 0.0117 \\
Total & 1.000 & 1.000 & 1.000 & 1.000 & 1.000 & 1.000 & 1.000 & 1.000 & 1.000 & 1.000 \\
\hline
\end{tabular}

Table 11: Weights of Criteria in sensitivity analysis.

\begin{tabular}{|c|c|c|c|c|c|c|c|c|c|c|}
\hline $\begin{array}{c}\text { Alternative } \\
\text { NF's }\end{array}$ & Normal & $\begin{array}{c}\text { Run } \\
0.1\end{array}$ & $\begin{array}{c}\text { Run } \\
0.2\end{array}$ & $\begin{array}{c}\text { Run } \\
03\end{array}$ & $\begin{array}{c}\text { Run } \\
0.4\end{array}$ & $\begin{array}{c}\text { Run } \\
0.5\end{array}$ & $\begin{array}{c}\text { Run } \\
0.6\end{array}$ & $\begin{array}{c}\text { Run } \\
0.7\end{array}$ & $\begin{array}{c}\text { Run } \\
0.8\end{array}$ & $\begin{array}{c}\text { Run } \\
0.9 \\
\end{array}$ \\
\hline $\mathrm{F}$ & 3 & 2 & 2 & 2 & 3 & 3 & 3 & 3 & 3 & 3 \\
\hline $\mathrm{H}$ & 6 & 4 & 6 & 6 & 6 & 7 & 7 & 8 & 9 & 9 \\
\hline $\mathrm{J}$ & 7 & 6 & 7 & 7 & 7 & 6 & 6 & 6 & 6 & 7 \\
\hline $\mathrm{K}$ & 10 & 10 & 10 & 10 & 10 & 10 & 9 & 9 & 8 & 8 \\
\hline $\mathrm{R}$ & 1 & 1 & 1 & 1 & 1 & 1 & 1 & 1 & 1 & 1 \\
\hline $\mathrm{O}$ & 8 & 7 & 8 & 8 & 8 & 9 & 10 & 10 & 10 & 10 \\
\hline $\mathrm{P}$ & 2 & 8 & 5 & 3 & 2 & 2 & 2 & 2 & 2 & 2 \\
\hline $\mathrm{C}$ & 12 & 12 & 12 & 12 & 12 & 12 & 12 & 12 & 12 & 12 \\
\hline I & 5 & 5 & 4 & 5 & 5 & 5 & 5 & 5 & 5 & 5 \\
\hline $\mathrm{CO}$ & 11 & 9 & 11 & 11 & 11 & 11 & 11 & 11 & 11 & 11 \\
\hline B & 4 & 3 & 3 & 4 & 4 & 4 & 4 & 4 & 4 & 4 \\
\hline $\mathrm{S}$ & 9 & 11 & 9 & 9 & 9 & 8 & 8 & 7 & 7 & 6 \\
\hline
\end{tabular}

Table 12: Ranking of alternative materials after weight modifications.

coefficient of ranks obtained using PIV method with the rank obtained using other method is shown in Table 10.

It is observed from Table 10 there is a strong correlation (correlation coefficient is nearly 1) between the ranks obtained using PIV method and other MCDM methods. Hence, it can be concluded that the results obtained using PIV method are similar to that of other five MCDM methods. This also support the consistency and reliability of PIV method.

\subsection{Sensitivity analysis}

Sensitivity analysis has been done to ensure that the obtained results do not show any biasness and also to purge the effect of the highest weight criterion on other criteria considered in the present study. A methodology available in the literature [52-54] to carry out sensitivity analysis has been used in the present research where weights of all criteria have been varied in proportion to the weight of the highest ranked criterion. In the present study since the top ranked criterion is stiffness as its weight is maximum i.e. 0.3274 and therefore, its weight has been varied from 0.1 to 0.9 and the weights of all other criteria have been calculated as presented in Table 11 .

In sensitivity analysis, the effect of changing weight on the ranking of alternative materials are observed as presented in Table 12.
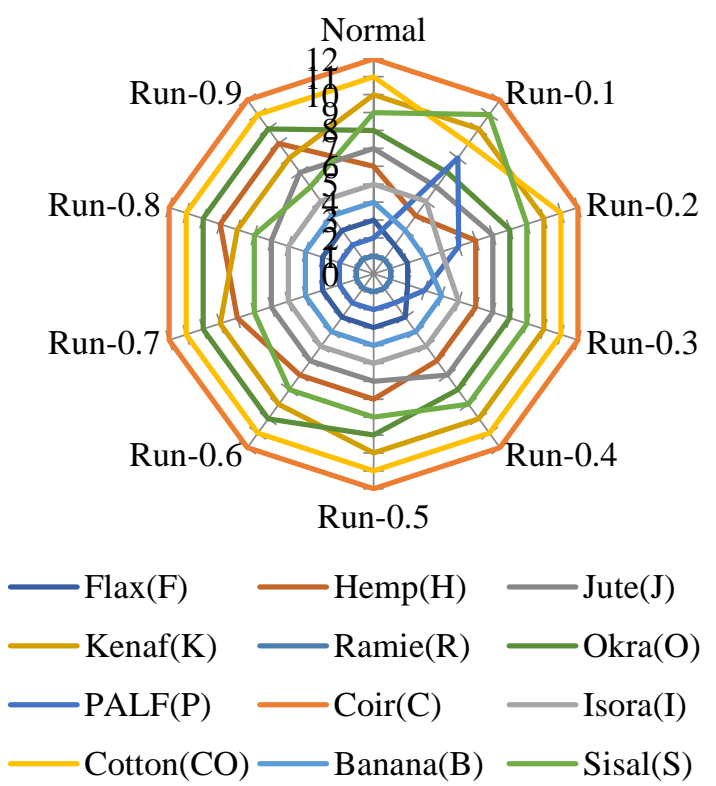

Figure 2: Ranking of alternatives in Sensitivity Analysis.

Table 12 clearly shows the ranking of alternative NF's by changing the weight of $S$, it can be clearly observed that on changing weight of $S$ from 0.1 to 0.9 ramie acquired first rank and Coir is placed at last which shows the reliability of the LGPMBWM-PIV method. Thus, it is verified that ramie is best alternative NF for composite fabrication of car roof whereas coir is worst choice for the same . Further, ranking of alternatives on varying the 
weight of criterion are shown in Figure 2 which clearly represent the variation of ranking of different alternatives.

\section{Conclusion}

In this study, selection of appropriate natural fibre for Car roof was successfully done by employing LGPMBWMPIV method. The ranking sequences obtained from PIV method suggest Ramie fiber as the most suitable alternative NFs for fabrication of NFCs used in manufacturing of car roofs whereas coir fiber being worst alternative NF. This ranking sequence was also supported by ranking obtained through PIV, WASPAS, EDAS, TOPSIS, ROV and COPRAS methods. Sensitivity Analysis results show that for any weight modification of criteria, the ranking of alternatives obtained from hybrid LGPMBWM-PIV method remains same which support the consistency and reliability of the method.

\section{Future work}

Automotive industries are engaged with the manufacturing of several complex components and each components involves the material selection. Thus, as a future research direction, hybrid LGPMBWM-PIV MCDM method can also be applied to the selection of other automotive components which will minimize the cost and time involve in their production.

\section{Acknowledgement}

Authors want to thanks to all the academic expert chose from Jamia milia Islamia, Delhi Technical University, Indian Institute of Technology-Delhi, University of Malaya, Altus Muhedisliki for their cooperation, understanding and consideration of questionnaire.

\section{References}

[1] L. Chapman (1997). Transport and climate change: a review, Int. J. Environ. Pollut.,7(3), 327-342.

[2] H. Helms, U. Lambrecht (2017). The potential contribution of light-weighting to reduce transport energy consumption, Int. J. Life Cycle Assess. 12(1), 58-64. http://dx.doi.org/10.1065/lca2006.07.258

[3] J.P Howell (1996). The side load distribution on a Rover 800 saloon car under crosswind conditions. J. Wind Eng. and Ind. Aero. 60, 139-153. https://doi.org/10.1016/0167-6105(96)00029-3

[4] P.M. Samuel, K. Robert D. Christopher, M.B (2010). Eileen Mortality and injury patterns associated with roof crush in rollover crashes. Accident Analysis and Prevention, 42. https://doi.org/10.1016/j.aap.2010.02.013

[5] F.M. Al-Oqla, S.M. Sapuan (2014). Natural fiber reinforced polymer composites in industrial applications: feasibility of date palm fibers for sustainable automotive industry. J. Cleaner Prod., 66, 347-354.

https://doi.org/10.1016/j.jclepro.2013.10.050
[6] F.M. AL-Oqla, S.M. Sapuan, M.R. Ishak, A.A. Nuraini (2015). A model for evaluating and determining the most appropriate polymer matrix type for natural fiber composites. Int. J. Polym. Anal. and Charact., 20(3), 191-205. https://doi.org/10.1080/1023666X.2015.990184

[7] F.M. Al-Oqla, S.M Sapuan, M.R Ishak, A.A. Nuraini (2016). A decision-making model for selecting the most appropriate natural fiber-Polypropylene-based composites for automotive applications. J. Compos. Mater., 50(4), 543-556. https://doi.org/10.1177/0021998315577233

[8] L.P. Maskepatil, A.U. Gandigude, S.A. Kale (2014). Selection of material for wind turbine blade by analytic hierarchy process (AHP) method. In Appl. Mech. Mater., 612,145-150.

https://doi.org/10.4028/www.scientific.net/AMM.6 12.145

[9] M. Luqman, M.U. Rosli, C.Y. Khor, S. Zambree, H. Jahidi (2018). Manufacturing Process Selection of Composite Bicycle's Crank Arm using Analytical Hierarchy Process (AHP). In IOP Conf. Ser. Mater. Sci. Eng., 318 (1), 012058. https://doi.org/10.1088/1757-899X/318/1/012058

[10] L. Anojkumar, M. Ilangkumaran, V. Sasirekha (2014). Comparative analysis of MCDM methods for pipe material selection in sugar industry, Expert Systems with Applications 41(6), 2964-2980. https://doi.org/10.1016/j.eswa.2013.10.028

[11] K. Anupam, P.S. Lal, V. Bist, A.K. Sharma, V. Swaroop (2014). Raw material selection for pulping and papermaking using TOPSIS multiple criteria decision making design. Environ. Prog. Sustainable Energy, 33(3), 1034-1041. https://doi.org/10.1002/ep.11851

[12] F.M. Al-Oqla, S.M. Sapuan, M.R. Ishak, A.A. Nuraini (2015). Decision making model for optimal reinforcement condition of natural fiber composites. FiberPolym., 16(1), 153-163. https://doi.org/10.1007/s12221-015-0153-3

[13] Majumdar, B. Sarkar, P.K. Majumdar (2004). Application of analytic hierarchy process for the selection of cotton fibers. FiberPolym., 5(4), 297 302. https://doi.org/10.1007/BF02875528

[14] M.K. Ozturk, O.B. Berkalp, B. Nergis (2017). Design of a light weight fabric from natural cellulosic fibers with improved moisture related properties. In IOP Conf. Ser.: Mater. Sci. Eng. 254 (18), 182005. https://doi.org/10.1088/1757-899X/254/18/182005

[15] R. Mohammed, B.R. Reddy, S. Kakarla, B.B. Krishna, M.P. Khan (2017). Mechanical Characterization \& TOPSIS Ranking of Glass Fiber Reinforced particulate filled Epoxy based Hybrid Composites. J. Chem. Pharm. Sci., Special, (2), 311 317.

[16] K. Jha, R. Kumar, K. Verma, B. Chaudhary, Y.K. Tyagi, S. Singh (2018). Application of modified TOPSIS technique in deciding optimal combination for bio-degradable composite. Vacuum, 157, 259267. https://doi.org/10.1016/j.vacuum.2018.08.063 
[17] S. Ahmad Fadli (2017). An integrated software quality model in a fuzzy analytical hierarchy process-based evaluation framework for e-learning software/Ahmad Fadli Saad(Doctoral dissertation, University of Malaya). http://studentsrepo.um.edu.my/id/eprint/8129

[18] N.M. Ishak, S.D. Malingam, M.R. Mansor (2016). Selection of natural fibre reinforced composites using fuzzy VIKOR for car front hood. Int. J. Mate. Product Technol., 53(3-4), 267-285.

[19] Chang, K. L. (2015). The use of a hybrid MCDM model for public relations personnel selection. Informatica, 26(3), 389-406.

[20] Chakraborty, S., Zavadskas, E. K. (2014). Applications of WASPAS method in manufacturing decision making. Informatica, 25(1), 1-20.

[21] Aliakbari Nouri, F., Khalili Esbouei, S., Antucheviciene, J. (2015). A hybrid MCDM approach based on fuzzy ANP and fuzzy TOPSIS for technology selection. Informatica, 26(3), 369-388.

[22] Keshavarz Ghorabaee, M., Zavadskas, E. K., Olfat, L., Turskis, Z. (2015). Multi-criteria inventory classification using a new method of evaluation based on distance from average solution (EDAS). Informatica, 26(3), 435-451.

[23] Ku, H., Wang, H., Pattarachaiyakoop, N., Trada, M. (2011). A review on the tensile properties of natural fiber reinforced polymer composites. Composites Part B: Engineering, 42(4), 856-873. https://doi.org/10.1016/j.compositesb.2011.01.010

[24] Saheb, D. N., Jog, J. P. (1999). Natural fiber polymer composites: a review. Advances in Polymer Technology: Journal of the Polymer Processing Institute, 18(4), 351-363. https://doi.org/10.1002/(SICI)10982329(199924)18:4<351::AID-ADV6>3.0.CO;2-X

[25] F. Yao, Q. Wu, Y. Lei, W. Guo, Y. Xu (2008). Thermal decomposition kinetics of natural fibers: activation energy with dynamic thermogravimetric analysis. Polym. Degrad. Stab. 93(1): 90-98. https://doi.org/10.1016/j.polymdegradstab.2007.10. 012 .

[26] S. Tsai (2018). Introduction to composite materials. Routledge.

[27] R. Latif, S. Wakeel, N.Z. Khan, A.N. Siddiquee, S.L. Verma Z.A. Khan (2018). Surface treatments of plant fibers and effects on mechanical properties of fiber-reinforced composites, J. Reinf. Plast. Compos. https://doi.org/10.1177/0731684418802022

[28] Pickering, K. L., Efendy, M. A., Le, T. M. (2016). A review of recent developments in natural fibre composites and their mechanical performance. Composites Part A: Applied Science and Manufacturing, 83, 98-112. https://doi.org/10.1016/j.compositesa.2015.08.038

[29] Akil, H., Omar, M. F., Mazuki, A. A. M., Safiee, S. Z. A. M., Ishak, Z. M., Bakar, A. A. (2011). Kenaf fiber reinforced composites: A review. Materials \& Design, 32(8-9), 4107-4121.

https://doi.org/10.1016/j.matdes.2011.04.008
[30] Thakur, V. K., Thakur, M. K., Gupta, R. K. (2014). raw natural fiber-based polymer composites. International Journal of Polymer Analysis and Characterization, 19(3), 256-271. https://doi.org/10.1080/1023666X.2014.880016

[31] Wang, W., Sain, M., Cooper, P. A. (2006). Study of moisture absorption in natural fiber plastic composites. Composites science and technology, 66(3-4), 379-386. https://doi.org/10.1016/j.compscitech.2005.07.027

[32] Athijayamani, A., Thiruchitrambalam, M., Natarajan, U., Pazhanivel, B. (2009). Effect of moisture absorption on the mechanical properties of randomly oriented natural fibers/polyester hybrid composite. Materials Science and Engineering: A, 517(1-2), 344-353. https://doi.org/10.1016/j.msea.2009.04.027

[33] Robertson, N. L. M., Nychka, J. A., Alemaskin, K., Wolodko, J. D. (2013). Mechanical performance and moisture absorption of various natural fiber reinforced thermoplastic composites. Journal of applied polymer science, 130(2), 969-980. https://doi.org/10.1002/app.39237

[34] R. Kumar, Ray (2015). A Selection of material under conflicting situation using simple ratio optimization technique. In: Proceedings of fourth international conference on soft computing for problem solving, advances in intelligent systems and computing, 335, 513-519. https://doi.org/10.1007/978-81-322-2217-0_42

[35] Komuraiah, N.S. Kumar, B.D. Prasad (2014). Chemical composition of natural fibers and its influence on their mechanical properties. Mech. Compos. Mater., 50(3), 359-376. https://doi.org/10.1007/s11029-014-9422-2

[36] S.P.S. Tita, R. Mederios, J.R. Tarpani (2018). Chemical modification of sugarcane baggase and sisal fibers using hydroxylmethylated lignin: Influence on Impact strength and water absorption of phenolic composites J. Compos. Mater. 52 (20), 2743-2753. https://doi.org/10.1177/0021998317753886

[37] M. Kracka, W.K.M. Brauers, E.K. Zavadskas (2010). Ranking heating losses in a building by applying the Multimoora. Eng. Econ. 21(4), 352359 .

[38] B.W. Rosen (1973). Stiffness of fibre composite materials. Composites, 4(1), 16-25. https://doi.org/10.1016/0010-4361(73)90291-7

[39] C. Scarponi, C.S. Pizzinelli (2009). Interface and mechanical properties of natural fibres reinforced composites: a review. International J. Mater. Product Technol., 36(1-4), 278-303.

[40] Amiri, M., Emamat, M. S. M. M. (2020). A Goal Programming Model for BWM. Informatica, 31(1), 21-34. https://doi.org/10.15388/20-INFOR389

[41] Rezaei J (2016). Best-worst multi-criteria decisionmaking method: Some properties and a linear model. Omega; 64, 126-130. https://doi.org/10.1016/j.omega.2014.11.009 
[42] Abadi F., Sahebi I., Arab A., Alavi A., Karachi H (2018). Application of best-worst method in evaluation of medical tourism development strategy. Decision Science Letters; 7(1), 77-86. 10.5267/j.dsl.2017.4.002

[43] Shojaei P., Haeri S. A. S., Mohammadi S (2018). Airports evaluation and ranking model using Taguchi loss function, best-worst method and VIKOR technique. Journal of Air Transport Management; 68, 4-13. https://doi.org/10.1016/j.jairtraman.2017.05.006

[44] Salimi N., Rezaei J (2018). Evaluating firms' R\&D performance using best worst method. Evaluation and program planning; 66, 147-155. https://doi.org/10.1016/j.evalprogplan.2017.10.002

[45] Gupta H (2018). Evaluating service quality of airline industry using hybrid best worst method and VIKOR. Journal of Air Transport Management; 68, 35-47. https://doi.org/10.1016/j.jairtraman.2017.06.001

[46] Ahmad W. N. K. W., Rezaei J., Sadaghiani S., Tavasszy L. A . (2017). Evaluation of the external forces affecting the sustainability of oil and gas supply chain using Best Worst Method. J. Cleaner Prod.; 153, 242-252. https://doi.org/10.1016/j.jclepro.2017.03.166

[47] Gupta H., Barua M. K. (2017). Supplier selection among SMEs on the basis of their green innovation ability using BWM and fuzzy TOPSIS. J. Cleaner Prod; 152, 242-258. https://doi.org/10.1016/j.jclepro.2017.03.125

[48] van de Kaa G., Kamp L., Rezaei, J (2017). Selection of biomass thermochemical conversion technology in the Netherlands: A best worst method approach. J. Cleaner Prod.; 166, 32-39.

https://doi.org/10.1016/j.jclepro.2017.07.052

[49] Rezaei J., Hemmes A., Tavasszy L (2017). Multicriteria decision-making for complex bundling configurations in surface transportation of air freight. Journal of Air Transport Management; 61, 95-105. https://doi.org/10.1016/j.jairtraman.2016.02.006

[50] Rezaei, J (2015). Best-worst multi-criteria decisionmaking method. Omega; 53, 49-57. https://doi.org/10.1016/j.omega.2014.11.009

[51] Mufazzal S., Muzakkir S. M. (2018). A new multicriterion decision making (MCDM) method based on proximity indexed value for minimizing rank reversals. Computers \& Industrial Engineering, 119, 427-438.https://doi.org/10.1016/j.cie.2018.03.045.

[52] Prakash C., Barua M. K (2015). Integration of AHPTOPSIS method for prioritizing the solutions of reverse logistics adoption to overcome its barriers under fuzzy environment. Journal of Manufacturing Systems; 37, 599-615. https://doi.org/10.1016/j.jmsy.2015.03.001

[53] Mangla S. K., Kumar P., Barua M. K (2015). Risk analysis in green supply chain using fuzzy AHP approach: a case study. Resour., Conserv. Recycl.; 104, 375-390.

https://doi.org/10.1016/j.resconrec.2015.01.001
[54] Triantaphyllou E (2000). A Sensitivity Analysis Approach for MCDM Methods. In Multi-criteria Decision Making Methods: A Comparative Study (pp. 131-175), Springer; Boston, MA. https://doi.org/10.1007/978-1-4757-3157-6_8

[55] Wakeel, S., Bingol, S., Bashir, M. N., \& Ahmad, S. (2020). Selection of sustainable material for the manufacturing of complex automotive products using a new hybrid Goal Programming Model for Best Worst Method-Proximity Indexed Value method. Proceedings of the Institution of Mechanical Engineers, Part L: Journal of Materials: Design and Applications, 1464420720966347. https://doi.org/10.1177/1464420720966347

[56] Wakeel, S., Ahmad, S., Bingol, S., Bashir, M. N., Paçal, T. C., \& Khan, Z. A. (2020, August). Supplier Selection for High Temperature Die Attach by hybrid Entropy-Range of Value MCDM Technique: A Semiconductor Industry. In $2020 \quad 21 \mathrm{st}$ International Conference on Electronic Packaging Technology (ICEPT) (pp. 1-5). IEEE. 10.1109/ICEPT50128.2020.9202994.

[57] Ahmad, S , Bingöl, S , Wakeel, S . (2020). A hybrid multi-criteria decision making method for robot selection in flexible manufacturing system. Middle East Journal of Science , 6 (2) , 68-77. https://doi.org/10.23884/mejs.2020.6.2.03 
